\title{
Primary Care and Telehealth Spending Differed Across Primary Care Specialties During COVID-19 Stay-at-Home Order
}

J Gen Intern Med 36(7):2191-3 DOI: $10.1007 / \mathrm{s} 11606-021-06853-y$

(c) Society of General Internal Medicine 2021

\section{INTRODUCTION}

The COVID-19 outbreak has disproportionately affected people with comorbid conditions and those in marginalized racial and ethnic groups. ${ }^{1,2}$ It has also prompted social distancing measures that disrupted care for patients through facility closures, restricted capacity, and delays in non-urgent care. ${ }^{3}$ Concerns about COVID-19 exposure in clinical settings may have also led patients to avoid necessary care. ${ }^{4}$ While early research has demonstrated a decline in ambulatory care visits along with a rapid uptick in telehealth service use, ${ }^{5,6}$ the impact of social distancing measures on primary care (PC) services among vulnerable populations, such as Medicaid enrollees and those receiving care in federally qualified health centers (FQHC), is unknown. On March 9, 2020, Rhode Island declared a state of emergency due to COVID-19, and on March 30 implemented a shelter-in-place order (the ORDER). We assessed the association of the ORDER with outpatient primary care and telehealth spending among Medicaid enrollees.

\section{METHODS}

We analyzed claims for all 155,428 members of Rhode Island's largest Medicaid managed care organization (57.9\% of Medicaid enrollees in the state). We focused on professional spending per member per week for primary care, defined as outpatient visits to family practice, pediatric, internal medicine, and obstetric and gynecologic $(\mathrm{OB} / \mathrm{GYN})$ specialties. We classified visits as occurring in FQHCs, independent or hospital-based clinics (Office), or as telehealth, which included telephone-only visits. We compared professional spending per member per week for visits between January and April of 2020 with a comparable period in 2019.

Received February 8, 2021

Accepted April 22, 2021

Published online May 7, 2021

\section{RESULTS}

We observed a $70.5 \%$ decline in primary care spending 6 weeks post-declaration, which was considerably higher for FQHCs as compared to office-based practices $(77.1 \%$ vs. $66.2 \%$ ) (Table 1). The decline in primary care spending also varied by specialty, ranging from $35.4 \%$ among $\mathrm{OB} / \mathrm{GYNs}$ to $79.8 \%$ for family practice clinicians. Among the four specialties, three showed larger declines within FQHCs $(87.3 \%$ for internal medicine, $55.7 \%$ for $\mathrm{OB} / \mathrm{GYN}$, and $78.3 \%$ for pediatrics, respectively) than in office-based practices $(72.3 \%$, $23.5 \%$, and $66.9 \%$ ). Spending on telehealth services increased in week 11 and markedly thereafter (Fig. 1). The use of telehealth varied across specialties; through week 16, 57.9\% of family practice and $57.7 \%$ of internal medicine professional spending was telehealth, compared with $40.5 \%$ of pediatrics and $12.6 \%$ of $\mathrm{OB} / \mathrm{GYN}$ spending. Among Medicaid subgroups, infants $(<1$ year $)$ had the smallest decline in PC spending following the ORDER (21.3\% decrease), and the decline was less for FQHCs than for office-based practices $(4.6 \%$ vs. $30.2 \%)$. For the other three subgroups, reductions in primary care spending were $12.1-20.3 \%$ greater among FQHCs as compared with office-based settings. All observed changes were statistically significant at $p<0.001$.

\section{DISCUSSION}

FQHCs experienced a greater decline in PC spending than office-based practices following the ORDER. These declines may have been driven by specific $\mathrm{FQHC}$ responses or by differences in patient care-seeking behavior across settings. Across all providers, spending decreases varied by specialty, with the smallest decrease in $\mathrm{OB} / \mathrm{GYN}$ care, perhaps due to providers prioritizing prenatal visits. Visits for infants only fell $21.3 \%$, suggesting further prioritization of infant care. Why some specialties (family medicine, internal medicine) were able to more rapidly convert to telehealth cannot be determined from our data. Research is needed to identify the factors driving these observed variations. Additionally, these results may not be generalizable to Medicaid populations in other states. While all patients benefit from social distancing recommendations and precautions, high-risk patients with chronic conditions may be more likely to experience adverse outcomes from lack of face-to-face care. Future research should 
Table 1 Six-Week Relative Changes in Outpatient Primary Care Spending and Proportion of Total Telehealth Spending, by Specialty and Medicaid Subgroup, March 9, 2020, through April 26, 2020

\begin{tabular}{|c|c|c|c|c|c|c|c|c|c|}
\hline \multirow[t]{2}{*}{ Location of visits } & \multicolumn{5}{|c|}{ Specialty } & \multicolumn{4}{|c|}{ Medicaid subpopulation } \\
\hline & Total & $\begin{array}{l}\text { Family } \\
\text { practice }\end{array}$ & $\begin{array}{l}\text { Internal } \\
\text { medicine }\end{array}$ & $\begin{array}{l}\text { OB/ } \\
\text { GYN }\end{array}$ & Pediatrics & $\begin{array}{l}\text { Medicaid } \\
(<1 \text { year })\end{array}$ & $\begin{array}{l}\text { Medicaid } \\
(1-5 \\
\text { years })\end{array}$ & $\begin{array}{l}\text { Medicaid } \\
(6-14 \\
\text { years })\end{array}$ & $\begin{array}{l}\text { Medicaid } \\
\text { (Female } \\
15-44 \text { years) }\end{array}$ \\
\hline $\begin{array}{l}\text { Total primary care } \\
\text { spending, } \% \\
\text { change }\end{array}$ & $\overline{7}-\overline{ }$ & -79.8 & -76.9 & -35.4 & -69.9 & -21.3 & -78.8 & -87.3 & -62.0 \\
\hline FQHC & $\overline{7}$ & -78.1 & -87.3 & -55.7 & -78.3 & -4.6 & -86.5 & -98.2 & -73.0 \\
\hline Office & & -82.4 & -72.3 & -23.5 & -66.9 & -30.2 & -74.4 & -81.7 & -52.7 \\
\hline Telehealth spending, $\%^{\mathrm{a}}$ & 46.5 & 57.9 & 57.7 & 12.6 & 40.5 & 20.6 & 35.3 & 47.3 & 42.7 \\
\hline
\end{tabular}

All observed changes are statistically significant at $p<0.001$

Abbreviations: $O B / G Y N$, obstetrics/gynecology; $F Q H C$, federally qualified health centers

${ }^{a}$ Percent of total spending made up by telehealth

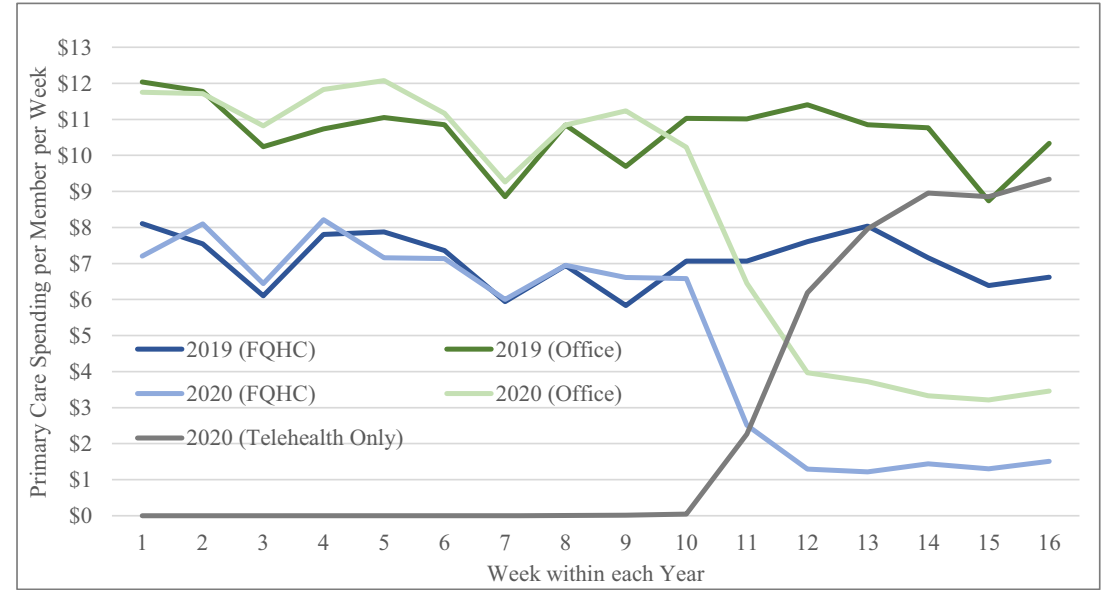

Figure 1 Trends in outpatient primary care spending for federally qualified health center, office-based practice and telehealth outpatient visits per member per week, 2019 vs. 2020. FQHC, federally qualified health center. 2019 data are from January 7, 2019, to April 28, 2019, and 2020 data are from January 6, 2020, to April 26, 2020.

investigate the factors that drove greater declines in $\mathrm{FQHC} \mathrm{PC}$ spending as compared to office-based practices including differences in patient care-seeking behavior across sites as well as related health outcomes.

Amanda Davis, $M P H^{1}$

Jacqueline Ellison, $\mathrm{PhD}^{2}$

Amal Trivedi, $M D^{2}$

Omar Galarraga, $\mathrm{PhD}^{2}$

Joanne Michaud, $\mathrm{MPH}^{2}$

Ira B. Wilson, $M D, M S c, F A C P^{2,3}$

${ }^{1}$ Boston University School of Public Health, Boston, MA, USA

${ }^{2}$ Brown University School of Public Health,

Providence, RI, USA

${ }^{3}$ Department of Health Services, Policy \& Practice, Brown School of Public Health,

Providence, RI, USA

Corresponding Author: Ira B. Wilson, MD, MSc, FACP; Department of Health Services, Policy \& Practice, Brown School of Public Health, Providence, RI, USA (e-mail: ira_wilson@brown.edu).
Funding This work was funded by a COVID-19 SEED grant from Brown University. Dr. Wilson is partially supported by the Providence/ Boston Center for AIDS Research (P3OAI042853) and by Institutional Development Award Number U54GM115677 from the National Institute of General Medical Sciences of the National Institutes of Health, which funds Advance Clinical and Translational Research (Advance-CTR) from the Rhode Island IDeA-CTR award (U54GM115677).

\section{REFERENCES}

1. COVID-19 Provisional Counts - Weekly Updates by Select Demographic and Geographic Characteristics. Published June 17, 2020. . https://www. cdc.gov/nchs/nvss/vsrr/covid_weekly/index.htm

2. Arasteh K. Prevalence of Comorbidities and Risks Associated with COVID19 Among Black and Hispanic Populations in New York City: an Examination of the 2018 New York City Community Health Survey [published online ahead of print, 2020 Aug 13]. J Racial Ethn Health Disparities. 2020. doi:https://doi.org/10.1007/s40615-020-00844-1

3. Lee CI, Raoof S, Patel SB, et al. Coronavirus Disease 2019 (COVID-19) and Your Radiology Practice: Case Triage, Staffing Strategies, and Addressing Revenue Concerns. J Am Coll Radiol. 2020;17(6):752-754. doi:https://doi. org/10.1016/j.jacr.2020.04.025

4. Carlos RC, Lowry K, Sadigh G. The Coronavirus Disease 2019 (COVID-19) Pandemic: A Patient-Centered Model of Systemic Shock 
and Cancer Care Adherence. $J$ Am Coll Radiol. Published online June 3, 2020. doi:https://doi.org/10.1016/j.jacr.2020.05.032

5. Mehrotra A, Chernew M, Linetsky D, Hatch H, Cutler D. What impact has COVID-19 had on outpatient visits. To the Point. 2020 Apr 23;23.
6. Ziedan E, Simon KI, Wing C. Effects of State COVID-19 Closure Policy on NON-COVID-19 Health Care Utilization. National Bureau of Economic Research; 2020. doi:https://doi.org/10.3386/w2762 1

Publisher's Note: Springer Nature remains neutral with regard to jurisdictional claims in published maps and institutional affiliations. 